\title{
Cooperativo, transnacional e regulador: o esquema de integração como um (novo) paradigma para a teoria do Estado
}

Cooperative, transnational and regulator: the integration scheme as a (new) paradigm for the State theory

Luciane Klein Vieira ${ }^{1}$

Maria Cândida Simon Azevedo ${ }^{2}$

\begin{abstract}
Resumo: O presente artigo se propõe a analisar o Direito da Integração como possível sucessor do projeto tradicional de Estado, com o surgimento de um novo paradigma político, que é cooperativo, transnacional e regulador. Para tanto, o problema de pesquisa gira em torno da seguinte questão: de que forma os esquemas de integração podem ser vistos como um novo paradigma de Estado, substituindo o antigo projeto por um novo de cooperação transnacional? Utilizando-se
\end{abstract}

1 Doutora em Direito (Área: Internacional) e Mestre em Direito Internacional Privado pela Universidad de Buenos Aires - UBA. Mestre em Direito da Integração Econômica pela Universidad del Salvador - USAL e Universitè Paris I - Panthéon Sorbone. E-mail: lucianekleinvieira@yahoo.com.br

2 Mestranda em Direito Público pela Universidade do Vale do Rio dos Sinos, na linha de pesquisa Sociedade, Novos Direitos e Transnacionalização. Especialista em Direito e Processo do Trabalho e Bacharel em Direito pela Universidade do Vale do Rio dos Sinos. Advogada.

E-mail: kandida8@hotmail.com 
do método dialético, o objetivo geral está relacionado ao estudo dos esquemas de integração, com o enfoque para um novo paradigma da teoria do Estado, apresentando-se como objetivos específicos: (1) fazer uma análise da modernidade e das modificações na estrutura do Estado; (2) descrever alguns esquemas de integração existentes, com vistas especialmente à União Europeia; (3) apontar as possibilidades de um novo paradigma de modelo de Estado, especificamente um Estado cooperativo, transnacional e regulador, decorrente da evolução dos esquemas de integração.

Palavras-chave: Direito da Integração. Estado nacional. Transnacionalização. Cooperação. Novo Paradigma.

Abstract: This article proposes to analyse the Integration Right as a possible successor of the traditional State project, with the emergence of a new political paradigm, which is cooperative, transnational and regulator. To that end, the research problem revolves around the following question: in what way the integration schemes can be seen as a new paradigm of the State, replacing the old project with a new one of transnational cooperation? Using the dialectical method, the general objective is related to the study of integration schemes with the focus on a new paradigm of State theory, presenting as specific objectives: (1) to make an analysis of modernity and changes in the structure of the State; (2) to describe existing integration schemes with a view in particular to the European Union; (3) to point out the possibilities of a new paradigm of State model, specifically a cooperative, transnational and regulator State arising from the evolution of integration schemes.

Keywords: Integration Right. National State. Transnationalization. Cooperation. New Paradigm. 


\section{Introdução}

O processo de globalização ${ }^{3}$ é fator que impulsiona a transformação de diversos setores e atores da sociedade, atingindo diretamente o Direito da Integração e o paradigma da Teoria de Estado. A transnacionalidade estatal, aqui, decorre dessas modificações que parecem inevitáveis para a sobrevivência do próprio Estado nacional.

Analisar o Direito da Integração como possível sucessor do projeto clássico ou tradicional de Estado é fundamental para entender o surgimento de um novo paradigma político, que é transnacional, regulador e cooperativo. Para tanto, importa a análise das teorias de grandes autores, principalmente Ulrich Beck ${ }^{4}$ e Jürgen Habermas ${ }^{5}$. A escolha dos mesmos se deu na medida em que ambos são sociólogos que estudam a realidade social, com vistas a propor novas possibilidades do que a sociedade poderia ser, buscando uma posição crítica.

Ademais, a partir de uma metodologia de análise bibliográfica e lançando mão do método de abordagem dialético, o presente estudo irá realizar uma apreciação, ainda que concisa, acerca das possibilidades que cada autor propõe, para no fim, chegar à síntese que melhor se adequa à análise proposta. Dessa forma, ao utilizarmos o método dialético é possível “[...] verificar com mais rigor os objetos de análise, justamente por serem postos frente a frente com o teste de suas contradições possíveis"

3 Sobre as mudanças causadas pela globalização em termos de ressignificação do conceito de soberania e as relações externas entre os Estados, ver: FORNASIER; MENDES, 2016, p. 533-570.

4 BECK, 2003, 1999, 2011.

5 HABERMAS, 2011, 2003, 2012a, 2012b.

6 MEZZAROBA; MONTEIRO, 2003, p. 72. 
Sem a pretensão de esgotar o tema proposto, o presente artigo visa responder ao seguinte problema de pesquisa: de que forma os processos de integração podem ser vistos como um novo paradigma de Estado, substituindo o antigo projeto por um novo de cooperação transnacional? Para tanto, objetiva-se um estudo dos processos de integração com enfoque destinado a contribuir para a formulação de um novo paradigma da Teoria do Estado.

Assim sendo, no item $\mathrm{n}^{\mathrm{o}} 2$, faremos uma análise da modernidade e do fenômeno da globalização, bem como das modificações da estrutura do Estado ocorridas a partir de uma visão proposta por Beck e Habermas, com vistas a explicar de que forma a globalização e a modernidade vêm transformando e ressignificando os paradigmas existentes.

No item $n^{\circ} 3$, nos propomos a descrever os processos de integração, em especial a União Europeia, a partir de uma análise do desenvolvimento desses esquemas, a fim de desvelar os objetivos propostos pelo Direito da Integração. Além disso, uma análise mais detida da União Europeia torna-se importantíssima para o desenrolar do item seguinte deste estudo, uma vez que essa serve como paradigma dos demais esquemas, em razão da profundidade do seu objetivo econômico e da sua estrutura orgânica supranacional.

Finalmente, objetiva-se apontar as possibilidades de um novo paradigma de modelo de Estado, especificamente um Estado transnacional, regulador e cooperativo, decorrente dos processos de integração. Para tanto há um retorno às teorias dos dois autores propostos inicialmente, a partir do qual se estudará o que ambos defendem no que toca à União Europeia e aos novos paradigmas decorrentes dessas transformações do Estado nacional.

Como se percebe, o tema deste estudo é importante para lançarmos mão de uma reanálise dos paradigmas 
existentes, tanto no tocante à Teoria do Estado, como com relação ao Direito da Integração, visando a uma atualização dos conceitos chaves de ambas as teorias, a partir do processo evolucionário referido.

\section{A nova modernidade e as modificações na estrutura do estado}

As origens do Estado nacional ${ }^{7}$, podem ser encontradas no que se entende por nação. ${ }^{8}$ Desde o seu surgimento, até o período da Idade Média, nação era relacionada a populações que ainda não teriam se reunido politicamente em uma organização estatal, mas que formavam comunidades, articuladas geograficamente, de acordo com linguagem, costumes e tradições comuns. Com a passagem para a Idade Moderna, o termo passa a estar relacionado com a soberania popular, ou seja, a nação como titular da soberania. ${ }^{9}$ Mais tarde, com a Revolução Francesa - século XVIII - o termo é empregado a partir de uma característica que constitui a identidade política dos sujeitos de uma determinada comunidade democrática. ${ }^{10}$

Atualmente, o então denominado Estado nacional, cujas origens representam, em especial, a característica da territorialidade, já não pode mais ser considerado o paradigma essencial das Teorias do Estado, ou seja, “a percepção do

7 Esclarecimento: Estado nacional, compreendido neste trabalho, diz respeito à concepção geopolítica europeia.

8 HABERMAS, 2003, p. 282.

9 Ressalta-se, ainda, que "desde a origem do Estado moderno, a partir das teorias dos primeiros contratualistas, formulou-se esta entidade abstrata que é o Estado, atribuindo-lhe a responsabilidade pela ordem social, jurídica, política e econômica, assim como para garantir o bem comum dos cidadãos" (SANTIN, 2015, p. 248).

10 HABERMAS, 2003, p. 282. 
Estado como sendo produtor único de normatividade jurídico-política no mundo, dotado de soberania inabalável dentro de fronteiras rígidas e totalmente controláveis, é algo que já não corresponde à realidade do mundo globalizado" ${ }^{11}$ Não é de hoje que grandes juristas e estudiosos vêm denunciando um possível colapso ou crise do mesmo. ${ }^{12}$ Em verdade, é um processo natural da humanidade alterar - constantemente - a forma de se relacionar entre si e de regular suas formas de poder.

Para entendermos esse constante movimento, é essencial realizarmos uma análise da época que estamos vivenciando. Um dos autores que melhor faz uma análise da modernidade é Beck ${ }^{13}$, trazendo novos conceitos para reflexões relacionadas à Segunda Modernidade ou Modernidade Reflexiva ${ }^{14}$, Individualismo Institucionalizado, Globalidade e Globalismo ${ }^{15}$, a fim de explicar o que ele chama de Sociedade do Risco ${ }^{16}$.

11 FORNASIER; MENDES, 2016, p. 562.

12 HABERMAS, 2003, p. 280.

13 BECK, 2003.

14 “O discurso sobre a 'Segunda Modernidade' ou 'modernização reflexiva' visa, antes de tudo, a uma autocrítica radical da teoria e da sociologia ocidentais da modernização" (BECK, 2003, p. 23).

15 "[...] esse vínculo entre globalização e neoliberalismo gera uma forma de globalismo que, qual rolo compressor, nivela de diversos modos" (BECK, 2003, p. 54). "Por globalismo eu designo a ditadura neoliberal do mercado mundial, que, particularmente no Terceiro Mundo, suprime os já escassos fundamentos do autodesenvolvimento democrático" (BECK, 2003, p. 23). Em outras palavras, "[...] designa a concepção de que o mercado mundial bane ou substitui, ele mesmo, a ação política; trata-se, portanto da ideologia do império do mercado mundial, da ideologia do neoliberalismo" (BECK, 1999, p. 27). Mas ainda, Beck ressalta que "[...] esse tipo de globalismo, ou seja, a ideologia segundo a qual o mercado pode resolver todos os problemas, é um dos perigos centrais da cultura democrática da diversidade. Pois esse modo de proceder conduz, em última instância, à ideia de substituir a política pelo mercado" (2003, p. 54).

16 Conforme Beck (2003, p. 24): "fica evidente que aquilo que nós chamamos 
Outro autor que também possui bem delineados os contornos da modernidade é Habermas ${ }^{17}$. Embora esse seja conhecido mais propriamente por sua teoria da democracia (procedimentalista), não pôde deixar de negar as transformações decorrentes desses novos paradigmas, inclusive no tocante às (novas) relações transnacionais estatais. A partir dessas concepções é que se pretende fazer uma abordagem da modernidade e as modificações decorrentes desta na estrutura do Estado nacional.

Interessante observar que, em que pese o que se nota à primeira vista, o termo Individualismo Institucionaliza$\mathrm{do}^{18}$, proposto por Beck ${ }^{19}$, não, necessariamente, remete ao individualismo a que estamos acostumados a relacionar ao termo, mas, sim, a um individualismo altruísta ou um egoísmo cooperativo. Em verdade, o que se nota é uma crescente onda de integração, ou seja, há uma espécie de individualismo cooperativo que vem se desenvolvendo des-

de natureza há muito se integrou ao processo de industrialização e vem se transformando em riscos e perigos que são negociados no processo de socialização e se desdobram em uma dinâmica política autônoma. Esse fato eu denomino sociedade do risco ou sociedade mundial do risco".

17 HABERMAS, 2001, 2012a.

18 Sobre a questão do individualismo decorrente da Segunda Modernidade, Beck (2003, p. 68) ressalta que este seria melhor denominado como individualismo institucionalizado, uma vez que esse individualismo, próprio das sociedades modernas, em verdade "[...] não se trata de uma forma de percepção do indivíduo isolado; trata-se, isto sim, de instituições centrais da sociedade moderna, como a necessidade de desenvolver uma biografia própria, de se despegar das predeterminações coletivas". Ademais, "isso se explica pelo fato de as instituições básicas centrais da sociedade, como a educação, os direitos sociais, políticos e civis, assim como as oportunidades de participação no mercado de trabalho e os processos de mobilidade, estarem voltadas para o indivíduo, não para o grupo ou a família" (BECK, 2003, p. 23). Em verdade, "trata-se, isto sim, de uma geração e de uma cultura que ousa experimentar um novo modo de conciliar o individualismo com a moral social e de vincular a voluntariedade e a individualidade a uma existência para os outros" (BECK, 2003, p. 77).

BECK, 2003, p. 76. 
de o início do século XXI, cujas raízes já foram lançadas há mais tempo. Em verdade, desde o final da Segunda Guerra Mundial podemos observar uma modificação na estrutura de relações interestatal e intraestatal, isto é, tanto na relação entre os Estados nacionais, quanto na relação interna destes com os seus cidadãos.

Para entendermos melhor de que forma a evolução da sociedade trouxe (e está trazendo) transformações que muitas vezes não entendemos, é necessário desvelar o que a Segunda Modernidade (Ulrich Beck) representa. Muitos autores preferem dizer que estamos em uma Pós Modernidade, entretanto, opta-se pela expressão Segunda Modernidade proposta por Beck, que fundamenta de forma clara e concisa a sua teoria. ${ }^{20}$

Primeiramente, importa salientar que não há um marco pontual que possa determinar a passagem da Primeira para a Segunda Modernidade, mas sim uma modificação gradual, que pode ser tão sorrateira que, muitas vezes, é imperceptível. Para Beck ${ }^{21}$, uma concepção de Pós Modernidade é um meio diagnóstico, aquilo que demonstra que não podemos mais nos amparar nos antigos conceitos, uma vez que não se traz nada de novo, isto é, não se busca desenvolver novos julgamentos e não se tenta reorganizar a sociedade. O que se

20 Em seu livro “Sociedade de Risco: rumo a uma outra modernidade”, Ulrich Beck (2011, p. 11) inicia, já no prefácio da obra, salientando que: "o tema deste livro é o discreto prefixo 'pós'. Ele é a palavra-chave de nossa época. Tudo é 'pós'. A 'pós-industrialismo' já nos acostumamos há algum tempo. Ainda lhe associamos alguns conteúdos. Com a 'pós-modernidade', tudo já começa a ficar mais nebuloso. Na penumbra conceitual do pós-esclarecimento, todos os gatos são pardos. 'Pós' é a senha para a desorientação que se deixa levar pela moda. Ela aponta para um além que não é capaz de nomear, enquanto, nos conteúdos, que simultaneamente nomeia e nega, mantém-se na rigidez do que já é conhecido. Passado mais 'pós' - essa é a receita básica com a qual confrontamos, em verborrágica e obtusa confusão, uma realidade que parece sair dos trilhos".

21 BECK, 2003, p. 20. 
faz, efetivamente, é apenas constatar que a sociedade sofreu uma transformação, mas não se procura reorganizá-la ou redefinir os seus conceitos da forma necessária.

No mesmo sentido, Habermas ${ }^{22}$ explica que, a partir de uma perspectiva da modernidade, é perceptível a necessidade de generalização das normas, que não mais podem estar atreladas a um conjunto de costumes fundamentais, rompendo com o paradigma moral que embasava o ordenamento jurídico. Então, ele entende que a partir dessa perspectiva, é necessário fazer um desmonte desse modelo pautado na razão prática (solipsista ${ }^{23}$ ), porque o mesmo é individualista e possui como visão de sociedade uma comunidade homogênea do ponto de vista ético ou moral.

Para Habermas ${ }^{24}$, apenas através do agir comunicativo (comunicação) é que a integração social pode funcionar em sociedades modernas, propondo o abandono do individualismo. Salienta que as sociedades modernas complexas exigem um agir comunicativo conduzido por interesses e neutralizado pelas normas, que estariam em condições de conduzir e promover a integração social. Para ele, "essa comunicação com força produtiva também é importante para os desafios da 'modernização reflexiva'" 25.26

22 HABERMAS, 2012a, p. 111-112.

23 Acerca dessa concepção de solipsismo ver Verdade e Consenso: constituição, hermenêutica e teorias discursivas de Lênio Streck (2017, p. 134), segundo o qual "a superação dessa consciência solipsista pode - e segundo Habermas, deve - ser substituída por um universo de comunicação em que não se comunicam indivíduos solipsisticamente, convictos cada um de sua posição (seria a razão prática), mas em que os indivíduos coletivamente trabalham sempre já com a antecipação de um discurso ideal. Ou seja, Habermas parte do pressuposto de que os atos ligados à razão prática são atos solipsistas, ligados à filosofia do sujeito, e, portanto, com estrutura prescritiva a priori, dependentes de fundamentação posterior".

24 HABERMAS, 2012a, p. 112.

25 HABERMAS, 2001, p. 196.

26 Além disso, Habermas (2001, p. 196) explica que “sociedades pós-industriais 
Deveras, essas alterações produzidas no centro da sociedade trazem inúmeras consequências, alterando significativamente o modo de interação social. Esse fato, por evidente, reflete tanto no próprio cidadão, através da alteração do modo de socialização, quanto no próprio Estado em si, uma vez que ambos têm que buscar alternativas para suprir necessidades emergentes. Por sua vez, um dos fatores que mais chamam a atenção nesse contexto é a desterritorialização da sociedade ${ }^{27}$, pensada a partir da ideia de globalização, na qual a vida na sociedade atual leva a uma cotidianidade global, ou seja, transnacional, passando-se, então, a repensar o que se pode imaginar hoje como o container do Estado nacional ${ }^{28} .{ }^{29}$

consumiram as reservas das quais a industrialização 'simples' havia se alimentado - tanto os recursos da natureza disponíveis, como também o capital cultural e social da formação social pré-moderna. Ao mesmo tempo nos defrontamos com as consequências secundárias da reprodução social, que atacam sob a figura de riscos gerados sistemicamente e que não podem mais ser exteriorizados, ou seja, transpostos para sociedades e culturas estrangeiras, para outros setores ou para gerações futuras. As sociedades modernas vão, em um duplo sentido, de encontro aos seus limites e tornamse 'reflexivas' quando percebem essa situação como tal e reagem a isso".

27 A respeito da transnacionalização das condutas ou internacionalização da vida em sociedade, é interessante trazer à colação o seguinte exemplo: “um taxista indiano em Chicago, por um lado, mora em Chicago, por outro, está estreitamente ligado ao seu país e manda dinheiro para lá, enquadrandose inclusive nas estruturas financeiras transnacionais, e, graças à televisão a cabo, é possível que também esteja integrado ao dia-a-dia do outro país. Quer dizer, ele já não vive 'isto ou aquilo', o neste ou no outro contêiner, mas constrói novas formas de vida transnacional, 'tanto isto quanto aquilo'" (BECK, 2003, p. 28).

28 Sobre o container do Estado nacional: “[...] as sociedades modernas se transformam em sociedades apartadas umas das outras, elas estão escondidas no território de poder do Estado nacional como se estivessem em um container. [...] O Estado procede tal como um container da unidade territorial, no qual sistematicamente são produzidas estatísticas dos processos e das situações econômica e social" (BECK, 1999, p. 53 e 54).

29 BECK, 2003, p. 43. 
Essa ideia de globalização na Segunda Modernidade torna-se irreversível, uma vez que a soberania e a identidade do Estado nacional passam a sofrer interferências de atores transnacionais. Ademais, o Estado se vê influenciado por diversos outros fatores, tais como a ampliação geográfica oportunizada pelo comércio internacional e pelos meios tecnológicos de informação e comunicação, a exigência universal da consolidação dos direitos humanos, a pobreza mundial, a destruição ambiental mundial, entre outros fatores. ${ }^{30} \mathrm{E}$ desse fato decorre "[...] que todas as descobertas, triunfos e catástrofes afetam a todo o planeta, e que devemos redirecionar e reorganizar nossas vidas e ações em torno do eixo 'global-local'"31.

Os principais aspectos desse processo de transformação estão no terreno econômico, no desenvolvimento de tecnologias da informação e redes, nos estilos de vida e no terreno político. Assim, como podemos perceber, o Estado de bem-estar social encontra-se em uma espécie de possível decadência, na medida em que se tornou excessivamente oneroso, sem contar que o Estado é um ator não mais decisivo, pois é dotado de prerrogativas soberanas apenas em um determinado território. ${ }^{32}$ Assim, essas prerrogativas soberanas territoriais são substituídas por uma " [...] multiplicidade de níveis normativos supra e transnacionais $[. . .]^{\prime \prime 33}$.

A partir dessas concepções, podemos questionar se não seria o fim da política, ou, mais possivelmente o fim da concepção que temos hoje da política. Neste sentido, Beck ${ }^{34}$ ressalta que, por evidente, a política organizada em termos

30 BECK, 1999, p. 30.

31 BECK, 1999, p. 30 e 31.

32 PETRUCCIANI, 2014, p. 215.

33 PETRUCCIANI, 2014, p. 215.

34 BECK, 2003, p. 43. 
territoriais - dentro do container do Estado nacional - vem perdendo força, uma vez que tanto o Estado quanto a sociedade estariam ainda empenhados no antigo jogo do poder entre capital, estado e trabalho. Ao contrário, a economia e outros setores já ingressaram em outra dimensão, isto é, em uma dimensão desterritorializada ou de subtração, uma vez que "a economia não é poderosa porque entra, mas porque pode sair. Porque pode bater em retirada" 35.36

A partir da perspectiva de um Estado nacional insuficiente para lidar com as necessidades do mundo globalizado, entra em cena o Direito Internacional, e aqui, mais especificamente, o Direito da Integração, razão pela qual importa analisarmos a atual conjectura dos esquemas de integração ${ }^{37}$ entre Estados nacionais, principalmente a partir de um olhar mais focado no paradigma de integração da União Europeia. Essa análise pretende oferecer uma visão diferenciada do que se entende hoje por Estado nacional, a partir de uma ideia de cooperação transnacional entre agentes estatais.

35 BECK, 2003, p. 44.

36 “[...] essa possibilidade de subtração da economia é uma vantagem oferecida pela tecnologia, ou seja, por meio da informática. Uma empresa pode fabricar seus produtos dispersando-se em vários continentes e já não depende de um lugar determinado para produzir. E esse poder de subtração é interessante porque representa justamente o oposto do poder territorial do Estado" (BECK, 2003, p. 44).

37 Prefere-se adotar a expressão "esquema de integração" nos termos do proposto por Sandra Negro (2010, p. 33): “Así, la denominación 'esquema de integración' se corresponde en forma más correcta con una descripción desde el punto de vista jurídico-institucional, mientras que la expresión 'proceso de integración regional' aparece mejor justificada desde un enfoque histórico-político". 


\section{Os esquemas de integração e o paradigma da união europeia}

Feito essa discussão conceitual inicial, vinculada à uma insuficiência dos paradigmas estatais, importa analisar alguns esquemas de integração, ou, mais especificamente, o surgimento destes e seus desdobramentos, com vistas essencialmente à uma melhor compreensão da União Europeia. Deveras, o Direito da Integração possuiu como um dos objetos iniciais a integração econômica entre Estados nacionais, com vistas, fundamentalmente, ao desenvolvimento do livre comércio em determinada região. Não obstante, muitos autores determinam que este ramo do Direito, na verdade, é proveniente do Direito Internacional Público, uma vez que, por exemplo, a constituição de um bloco econômico decorre de tratado internacional entre Estados soberanos, que se utilizam dos procedimentos clássicos ${ }^{38}$ previstos na Convenção de Viena sobre Direito dos Tratados, de 1969, para poder colocar em funcionamento a zona integrada.

Como resposta aos impactos da globalização na ordem internacional e, também, em decorrência do clima de estranhamento entre os Estados, que pairava desde o final do século XIX e início do século XX, surge uma onda de criação de esquemas de integração. ${ }^{39}$ Estes, ainda que à época em estado embrionário, passaram a modificar a relação entre os

38 MACHADO, 2013, p. 31.

39 Conforme explica Sandra Negro (2010, p. 37), “El objetivo de poner fin a una historia marcada por una profunda rivalidad entre Francia y Alemania fue lo que impulsó la integración en Europa en el primer capítulo que culminó con la creación de la CECA. En América del Sur, los conflictos que habían tenido un peso considerable en las relaciones entre Argentina y Brasil o entre Argentina y Chile disminuyeron progresivamente y de conformidad con la exploración de formas de cooperación y, más tarde, de integración económica". 
Estados através de alguns líderes que plantaram as sementes da integração mundial, tais como Robert Schuman ${ }^{40}$, George Marshall $^{41}$ e Winston Churchill ${ }^{42}$, dentre muitos outros que contribuíram para esse avanço, sendo que, para muitos, Jean Monnet ${ }^{43}$, na verdade, é considerado o precursor da integração regional.

Após o final das grandes guerras mundiais, sobretudo na Europa, muitos países encontravam-se sem forças para sua reconstrução, mas, apoiados na ideia de cooperação recíproca para o atingimento de um objetivo comum, com o

40 Robert Shuman (1950), então Ministro francês de Assuntos Exteriores, assim se manifestou acerca da integração regional da Europa: "La paz mundial no puede salvaguardarse sin unos esfuerzos creadores equiparables a los peligros que la amenazan. [...] La puesta en común de las producciones de carbón y de acero garantizará inmediatamente la creación de bases comunes de desarrollo económico, primera etapa de la federación europea, y cambiará el destino de esas regiones, que durante tanto tiempo se han dedicado a la fabricación de armas, de las que ellas mismas han sido las primeras víctimas. [...]Mediante la puesta en común de las producciones básicas y la creación de una Alta Autoridad de nuevo cuño, cuyas decisiones obligarán a Francia, Alemania y los países que se adhieran, esta propuesta sentará las primeras bases concretas de una federación europea indispensable para la preservación de la paz" (SHUMAN, 1950).

41 Conforme se advertiu, oportunamente: "El remedio consiste en romper el círculo vicioso y restaurar la confianza de la gente europea en el futuro económico de sus propios países y de Europa como un todo. El fabricante y el granjero a lo largo y ancho de amplias áreas tiene que tener capacidad y voluntad de cambiar sus productos por monedas cuyo valor continuo no esté constantemente en cuestión" (MARSHALL, 1947).

42 Sustentava-se que: "o nosso objetivo permanente deve ser construir e fortalecer o poder da Organização das Nações Unidas. Ao abrigo deste conceito mundial e no seu seio devemos recriar a família europeia numa estrutura regional chamada, por exemplo, de Estados Unidos da Europa" (CHURCHILL, 1946).

43 "Jean Monnet - a força unificadora por trás do nascimento da União Europeia. O consultor econômico e político francês Jean Monnet dedicou a sua vida à causa da integração europeia, tendo sido o inspirador do «Plano Schuman», que previa a fusão da indústria pesada da Europa Ocidental". (UNIÃO EUROPEIA, 2017b, grifo do autor). 
intuito inicial de preservar a paz entre as nações e buscar uma melhoria na qualidade de vida dos seus cidadãos fizeram com que o nacionalismo exacerbado, até então prevalecente, cedesse passo à ideia de integração e de solidariedade, como condição para a sua sobrevivência no novo e desconhecido cenário global.

Nesta esteira, como é cediço, a precursora da integração foi a União Europeia (UE). Entretanto, antes mesmo já podíamos perceber o surgimento de esquemas de integração, ainda que precários, como, por exemplo, a Comunidade das Nações (Commonwealth), que engloba cerca de 50 Estados e pode ser classificada como um sistema de preferências tarifárias ${ }^{44}$. Muitos discutem se efetivamente se trata de uma zona integrada, em termos econômicos, já que se formou a partir de ex-colônias da Inglaterra, que mantêm entre si uma relação de amizade e de cooperação para assuntos de diversas índoles, principalmente em aspectos políticos e sociais, não sendo o aspecto econômico o mais relevante.

Como se pode notar, o Direito da Integração tem sua emergência a partir desse transbordamento das fronteiras territoriais e das relações sociais no interior do Estado nacional, que propiciou o surgimento de uma sociedade transnacional, pautada na interação entre diversos grupos sociais, tais como profissionais, empresas, sindicatos, entidades acadêmicas, comunidades científicas, entre outras. ${ }^{45}$ Essa evidente transformação social forçou (e está forçando) os Estados nacionais a moldarem formas de integração que, em sua grande maioria, desaguam nos esquemas de integração regional.

Atualmente, existe a classificação de seis denominados modelos de integração econômica - embora haja divergên-

44 OCAMPO, 2008, p. 29.

45 OCAMPO, 2008, p. 28. 
cias doutrinárias neste tocante -, isto é, zona de preferências tarifárias, zona de livre comércio, união aduaneira, mercado comum, união econômica e integração total, sendo que essas demonstram o grau ou a intensidade da integração. ${ }^{46}$ $\mathrm{Na}$ realidade, atualmente podemos perceber, além destes, esquemas de integração que não respeitam às classificações doutrinárias preestabelecidas, uma vez que essas, em verdade, possuem cunho eminentemente econômico.

Além desses modelos, os esquemas de integração ainda podem ser classificados como intergovernamentais ou supranacionais, sendo que a primeira classificação está adstrita basicamente ao Direito da Integração, seguindo as regras de Direito Internacional Público. ${ }^{47}$ A supranacionalidade estaria mais vinculada ao chamado Direito Comunitário, que visa, essencialmente, regulamentar esquemas de integrações complexos e mais profundos, o que faz com que tal disciplina tenha basicamente aplicação apenas no bloco de integração da UE, uma vez que essa é considerada sua criadora, ${ }^{48}$ ainda que em outros espaços integrados seja possível vislumbrar-se características de supranacionalidade, como é o caso da Comunidade Andina de Nações (CAN) e da Comunidade do Caribe (CARICOM). ${ }^{49}$

46 OCAMPO, 2008, p. 28.

47 Ressalta-se que "o Direito Comunitário ou da União não se confunde com o Direito da Integração. Embora afins em alguns aspectos, não são disciplinas idênticas, não são sinônimos, versam sobre objetos diversos, tratam de conceitos próprios e abordam normas distintas. O Direito Comunitário pode até ser considerado uma forma de Direito da Integração aperfeiçoado, evoluído". (MACHADO, 2013, p. 31).

48 MACHADO, 2013, p. 35.

49 Segundo a doutrina: “o modelo comunitário europeu já começou a influenciar outros blocos; um importante exemplo é o da Comunidade Andina de Nações (CAN), que optou por molde semelhante ao europeu em seu documento constitutivo, ainda que muito precise ser feito para que possa ser considerada comunidade inteiramente regulada pelo Direito 
Assim, integrações como, por exemplo, o recente Proyecto Mesoamérica, cuja finalidade inicial é a integração entre os países membros com o intuito de melhoria da qualidade de vida de seus cidadãos, não podem ser facilmente enquadradas nos modelos clássicos ou tradicionais aludidos. Referido esquema trabalha a partir da criação de projetos com vistas a melhorias em determinados setores, tais como desenvolvimento humano, energia, turismo, telecomunicações, facilitação do comércio e competitividade, desenvolvimento sustentável, transporte e prevenção e diminuição de desastres naturais. Cada país contribui mais naquilo que melhor pode auxiliar no desenvolvimento do projeto, sendo que cada Estado membro implementa locais estratégicos de acesso à população, nos quais é possível, inclusive, a solicitação de implementações de novos projetos que sejam necessários à satisfação das necessidades da comunidade local. ${ }^{50}$

Assim também, o Mercado Comum do Sul - MERCOSUL ${ }^{51}$ é um esquema de integração que, ao lado de outros tantos, buscou seguir o modelo da UE, propondo a constituição de um mercado comum, pautado na livre circulação de mercadorias, serviços, fatores de produção e investimentos estrangeiros, mas que ainda não se perfectibilizou, na medida em que é considerado, atualmente, uma união aduaneira imperfeita. Isso ocorre, entre outras razões, em virtude da inexistência de efeito direto e aplicabilidade imediata ao direito originário e derivado do bloco, que precisa passar pelo procedimento de internalização em cada Estado Parte, a fim

Comunitário". (MACHADO, 2013, p. 34).

50 PROYECTO MESOAMÉRICA, 2016.

51 Importa ressaltar que, para além do interesse econômico, "o marco histórico da integração da América Latina pontua uma longa história de realizações, objetivando a união dos povos, com princípios jurídicos e institucionais, afirmação do processo democrático, com a geração de empregos qualificados e aumento da produtividade" (BIJOS, 2017, p. 225). 
de surtir efeitos, o que dificulta sobremaneira a integração. ${ }^{52}$

52 Nesse sentido, importa ressaltar decisão do Supremo Tribunal Federal brasileiro, no qual houve manifestação da Corte, no sentido de que o MERCOSUL é um esquema de integração intergovernamental: "MERCOSUL - CARTA ROGATÓRIA PASSIVA - DENEGAÇÃO DE EXEQUATUR - PROTOCOLO DE MEDIDAS CAUTELARES (OURO PRETO/MG) INAPLICABILIDADE, POR RAZÕES DE ORDEM CIRCUNSTANCIAL - ATO INTERNACIONAL CUJO CICLO DE INCORPORAÇÃO, AO DIREITO INTERNO DO BRASIL, AINDA NÃO SE ACHAVA CONCLUÍDO À DATA DA DECISÃO DENEGATÓRIA DO EXEQUATUR, PROFERIDA PELO PRESIDENTE DO SUPREMO TRIBUNAL FEDERAL - RELAÇÕES ENTRE O DIREITO INTERNACIONAL, O DIREITO COMUNITÁRIO E O DIREITO NACIONAL DO BRASIL - PRINCÍPIOS DO EFEITO DIRETO E DA APLICABILIDADE IMEDIATA - AUSÊNCIA DE SUA PREVISÃO NO SISTEMA CONSTITUCIONAL BRASILEIRO - INEXISTÊNCIA DE CLÁUSULA GERAL DE RECEPÇÃO PLENA E AUTOMÁTICA DE ATOS INTERNACIONAIS, MESMO DAQUELES FUNDADOS EM TRATADOS DE INTEGRAÇÃO - RECURSO DE AGRAVO IMPROVIDO. A RECEPÇÃO DOS TRATADOS OU CONVENÇÕES INTERNACIONAIS EM GERAL E DOS ACORDOS CELEBRADOS NO ÂMBITO DO MERCOSUL ESTÁ SUJEITA À DISCIPLINA FIXADA NA CONSTITUIÇÃO DA REPÚBLICA. - A recepção de acordos celebrados pelo Brasil no âmbito do MERCOSUL está sujeita à mesma disciplina constitucional que rege o processo de incorporação, à ordem positiva interna brasileira, dos tratados ou convenções internacionais em geral. É, pois, na Constituição da República, e não em instrumentos normativos de caráter internacional, que reside a definição do iter procedimental pertinente à transposição, para o plano do direito positivo interno do Brasil, dos tratados, convenções ou acordos - inclusive daqueles celebrados no contexto regional do MERCOSUL - concluídos pelo Estado brasileiro. Precedente: ADI 1.480-DF, Rel. Min. CELSO DE MELLO. - Embora desejável a adoção de mecanismos constitucionais diferenciados, cuja instituição privilegie o processo de recepção dos atos, acordos, protocolos ou tratados celebrados pelo Brasil no âmbito do MERCOSUL, esse é um tema que depende, essencialmente, quanto à sua solução, de reforma do texto da Constituição brasileira, reclamando, em consequência, modificações de jure constituendo. Enquanto não sobrevier essa necessária reforma constitucional, a questão da vigência doméstica dos acordos celebrados sob a égide do MERCOSUL continuará sujeita ao mesmo tratamento normativo que a Constituição brasileira dispensa aos tratados internacionais em geral. (Grifo nosso) PROCEDIMENTO CONSTITUCIONAL DE INCORPORAÇÃO DE CONVENÇÕES INTERNACIONAIS EM GERAL E DE TRATADOS DE INTEGRAÇÃO (MERCOSUL). - A recepção dos tratados internacionais em geral e dos acordos celebrados pelo Brasil no âmbito do MERCOSUL depende, para efeito de sua ulterior execução no plano interno, de uma 


\section{Outro exemplo de esquema de integração é o NAFTA, constituído em 1992 pelo Tratado Norte Americano de Livre Comércio, celebrado entre Estados Unidos, México e Cana-}

sucessão causal e ordenada de atos revestidos de caráter político-jurídico, assim definidos: (a) aprovação, pelo Congresso Nacional, mediante decreto legislativo, de tais convenções; (b) ratificação desses atos internacionais, pelo Chefe de Estado, mediante depósito do respectivo instrumento; (c) promulgação de tais acordos ou tratados, pelo Presidente da República, mediante decreto, em ordem a viabilizar a produção dos seguintes efeitos básicos, essenciais à sua vigência doméstica: (1) publicação oficial do texto do tratado e (2) executoriedade do ato de direito internacional público, que passa, então - e somente então - a vincular e a obrigar no plano do direito positivo interno. Precedentes. O SISTEMA CONSTITUCIONAL BRASILEIRO NÃO CONSAGRA O PRINCÍPIO DO EFEITO DIRETO E NEM O POSTULADO DA APLICABILIDADE IMEDIATA DOS TRATADOS OU CONVENÇÕES INTERNACIONAIS. - A Constituição brasileira não consagrou, em tema de convenções internacionais ou de tratados de integração, nem o princípio do efeito direto, nem o postulado da aplicabilidade imediata. Isso significa, de jure constituto, que, enquanto não se concluir o ciclo de sua transposição, para o direito interno, os tratados internacionais e os acordos de integração, além de não poderem ser invocados, desde logo, pelos particulares, no que se refere aos direitos e obrigações neles fundados (princípio do efeito direto), também não poderão ser aplicados, imediatamente, no âmbito doméstico do Estado brasileiro (postulado da aplicabilidade imediata). - O princípio do efeito direto (aptidão de a norma internacional repercutir, desde logo, em matéria de direitos e obrigações, na esfera jurídica dos particulares) e o postulado da aplicabilidade imediata (que diz respeito à vigência automática da norma internacional na ordem jurídica interna) traduzem diretrizes que não se acham consagradas e nem positivadas no texto da Constituição da República, motivo pelo qual tais princípios não podem ser invocados para legitimar a incidência, no plano do ordenamento doméstico brasileiro, de qualquer convenção internacional, ainda que se cuide de tratado de integração, enquanto não se concluírem os diversos ciclos que compõem o seu processo de incorporação ao sistema de direito interno do Brasil. Magistério da doutrina. - Sob a égide do modelo constitucional brasileiro, mesmo cuidando-se de tratados de integração, ainda subsistem os clássicos mecanismos institucionais de recepção das convenções internacionais em geral, não bastando, para afastá-los, a existência da norma inscrita no art. $4^{\circ}$, parágrafo único, da Constituição da República, que possui conteúdo meramente programático e cujo sentido não torna dispensável a atuação dos instrumentos constitucionais de transposição, para a ordem jurídica doméstica, dos acordos, protocolos e convenções celebrados pelo Brasil no âmbito do MERCOSUL." (BRASIL, 1998). 
dá. Este possui finalidade especialmente econômica, sendo, portando, classificado como uma zona de livre comércio, sem possuir interesses que possam levar a um aprofundamento na integração regional.

Apesar dos vários modelos de integração existentes, para este estudo, tomaremos como paradigma aquele proposto pela UE, protótipo dos esquemas de integração, que é hoje a única classificada como uma união econômica e monetária, mas que, entretanto, ainda desperta calorosas controvérsias doutrinárias acerca de sua classificação ${ }^{53}$, tendo em vista os objetivos aos quais se destina.

Importa ressaltar que antes da instituição propriamente dita da UE, mais especificamente em 1951, houve a iniciativa da criação da Comunidade Europeia do Carvão e do Aço $(\mathrm{CECA})^{54}$, que passou a unir econômica e politicamente países daquela região, nos setores referidos, o que foi de extrema importância para reerguer a Europa. Posteriormente, em 1957, foram assinados os tratados para instituição da Comunidade Econômica Europeia (CEE) e da Comunidade Europeia de Energia Atômica (Euratom). As três comunidades passaram a utilizar a regra da aplicabilidade imediata das suas normas, principalmente a partir da atuação do Tribunal de Justiça, ${ }^{55}$ com sede em Luxemburgo, o que lhes conferia um caráter que beirava a supranacionalidade, já na época. Mais tarde - 1992 - houve nova negociação entre os Estados, que resultou na assinatura do Tratado de Maastricht,

53 OCAMPO, 2008, p. 34.

54 “O Tratado que institui a Comunidade Europeia do Carvão e do Aço (CECA) foi assinado em Paris em 18 de Abril de 1951 pela Bélgica, Alemanha, França, Itália, Luxemburgo e Países Baixos. Concluído por um período de cinquenta anos e em virtude de ter entrado em vigor em 23 de Julho de 1952, chega ao seu termo em 23 de Julho de 2002". (UNIÃO EUROPEIA, 2017c).

55 Sobre a atuação do Tribunal referido e a consolidação dos princípios do Direito da UE, ver: VIEIRA, 2013, p.23-68. 
que finalmente instituiu a atual UE, como já referido, cujo objetivo principal foi transcender ao mero mercado comum já existente e adquirir uma nova dimensão econômica e também política. ${ }^{56}$

Há algum tempo a UE é considerada estável para os países do bloco e para os mais de 340 milhões de cidadãos que lá vivem, contribuindo consideravelmente para a melhoria de sua qualidade de vida. A supressão das fronteiras entre os Estados membros a partir do principal motor da economia - consolidação do mercado comum - trouxe ao bloco inúmeros benefícios, especialmente a partir da adoção do euro. ${ }^{57}$

Assim sendo, no que toca à UE e ao objeto deste artigo, o fato que mais chama a atenção é a adoção de um Parlamento Europeu e de outros órgãos supranacionais que, de uma forma ou de outra, poderiam ser equiparados aos Poderes Legislativo, Executivo e Judiciário, mas com atuação transnacional. Além disso, a adoção de uma moeda comum - o euro - pela maior parte dos Estados Membros, bem como a negociação que se estabeleceu, visando a adoção de uma Constituição para a Europa, em 2009, demonstram que esse esquema de integração está transcendendo as estruturas do Estado.

Uma das principais discussões que se tem com relação a este esquema de integração diz respeito à sua qualidade

56 Importa ressaltar que: “O Tratado da União Europeia (TUE) constituiu uma nova etapa na integração europeia, dado ter permitido o lançamento da integração política. Este Tratado criou uma União Europeia assente em três pilares: as Comunidades Europeias, a Política Externa e de Segurança Comum (PESC) e a cooperação policial e judiciária em matéria penal (JAI). Instituiu igualmente a cidadania europeia, reforçou os poderes do Parlamento Europeu e criou a União Económica e Monetária (UEM). Além disso, a CEE passou a constituir a Comunidade Europeia (CE)" (TRATADO, 2010).

57 UNIÃO EUROPEIA, 2017a. 
federativa ou não. Ou seja, existe muita especulação ao redor da ideia de que a UE já tenha alcançado um nível de Superestado, falando-se, inclusive, que um futuro passo seria a criação de uma confederação de Estados. Entretanto, as recentes discussões no que toca à política transnacional apontam para a existência de uma crise que pode levar à fragmentação da UE, ${ }^{58}$ isto é, crise de identidade, ressurgimento do nacionalismo e um provável déficit democrático, verificados especialmente a partir do denominado Brexit ${ }^{59}$ - saída do Reino Unido da UE.

Inobstante essa questão, que, apesar de não ser ignorada, não será objeto do presente estudo, o fato é que a UE em muito já superou os objetivos econômicos propostos, trabalhando, na atualidade, em questões que transcendem esse viés, como é o caso, por exemplo, da abordagem comunitária a problemas sociais derivados da adoção de uma política migratória comum. Nesse sentido, é interessante trazer à colação a provocação proposta por Habermas ${ }^{60}$, para quem: "nesta crise atual, indaga-se muito sobre a razão de ainda nos atermos ao projeto da União Europeia, vale dizer, ao antigo objetivo de uma 'união política cada vez mais estreita', no momento em que se esgotou justamente aquele motivo originário de impedir guerras na Europa".

A partir dessa reflexão, a seguir, proporemos o estudo de um novo projeto político a partir do modelo da UE, com vistas à superação do conceito clássico de Estado nacional.

58 Sobre o tema, e especificamente sobre o desenvolvimento de teorias de (des) integração regional, ver: VESPAZIANI, 2017, p. 13-29.

59 Como é sabido, em 23 de junho de 2016, os britânicos votaram a favor da saída do Reino Unido do bloco europeu. Em 29 de março do ano seguinte, o Reino Unido notificou formalmente o Conselho Europeu da sua intenção de se retirar da UE, havendo então acionado o art. 50 do Tratado de Lisboa. Para maiores informações sobre o Brexit, ver: VIEIRA, 2016, p. 87-104.

60 HABERMAS, 2012b, p. 39. 


\section{Um (novo) projeto político transnacional, regulador e cooperativo}

A teoria política ainda tem suas raízes agarradas aos paradigmas da territorialidade e da soberania estatal, mas ambos estão sofrendo um processo de readequação ou de transmutação, como já referido. Em verdade, desde o surgimento da UE, a soberania estatal foi substancialmente modificada, naquela região, a partir da atribuição de supranacionalidade às instituições comunitárias. Essa característica vem se desenvolvendo de forma gradual, a partir da chamada tese funcionalista, segundo a qual haveria a superação do conceito de soberania absoluta por intermédio do princípio da gradualidade, ou seja, da passagem gradativa de parcela da soberania dos Estados para a UE.

Ocorre que essa soberania submetida à integração regional vem despertando distintas teses no que toca à identidade conferida a estes esquemas, mais propriamente à UE, que é o mais avançado de todos. Assim, nossa inquietude diz respeito ao enquadramento que se pode dar à UE atual, isto é, o bloco caminha na direção da conformação de um Superestado, ou nada mais é que um esquema de integração evoluído, e que continuamente busca o aprofundamento dessa coesão entre os Estados Membros? O que se observa é uma necessidade de valer-nos de estruturas clássicas para responder a essa pergunta, ao passo que, na verdade, as novas necessidades transcendem esses limites e requerem uma nova abordagem, com a utilização de conceitos que possam mostrar-se satisfatórios, a fim de abranger a evolução política e social ocorrida, na região.

Dessa forma, muito se questiona acerca da necessidade de existir uma Constituição para a UE, mas encontra-se a existência de muitos óbices para a sua concretização. Não é 
de hoje que esse esquema de integração buscou transcender os limites do Direito Comunitário em que estaria enquadrado e do próprio Direito da Integração, principalmente a partir da propositura de uma Constituição. ${ }^{61}$ Entretanto, interessante se faz o seguinte questionamento: "é possível pensar-se uma Constituição criada a partir de mecanismos de negociação que, sob os moldes do direito internacional tradicional, apoiaria sua legitimidade em potestades inerentes ao Poder Executivo?" 62 .

Isso demonstra a necessidade de transcender o Direito da Integração e buscar respostas também em outros ramos do Direito, de forma conjunta, e investigar de que maneira podemos obter legitimidade política em domínios transnacionais. Por evidente que, para obter-se uma Constituição - no sentido dado pelo Direito Constitucional -, necessário é o preenchimento de alguns requisitos, como, primeiramente, um poder constituinte, que é, “ [...] em suma, o poder constituinte do povo, da nação, do Estado em sua manifestação mais profunda"63.64 Importa ressaltar que "[...] o Poder

61 Em verdade, "a formação de um acordo de vontades bilateral ou multilateral por intermédio de um Tratado decorre de um iter complexo, que pode ser observado a partir de dois pontos de observação: desde o próprio Direito das Gentes, distinguindo quais os indivíduos que, diante da comunidade internacional, podem negociar em representação de um Estado ou Organização Internacional (competência negocial). E, desde o direito público interno de cada Estado soberano, definindo a legitimidade que confere a ordem constitucional para um tratado ser concluído, e, assim, obrigar ao Estado internacionalmente (treaty making power). Tanto em um como em outro, a capacidade para negociar e celebrar tratados encontra-se concentrada na figura do Poder Executivo" (SCHWARTZ; MEINERO, 2017, p. 135).

62 SCHWARTZ; MEINERO, 2017, p. 135.

63 BONAVIDES, 2013, p. 53.

64 "A crítica à Constituição Europeia é fundamentada basicamente na suposta ilegitimidade da Convenção em redigir o texto constitucional, já que os "constituintes" da conferência não foram eleitos democraticamente, ou 
Constituinte Originário a ninguém se encontra subjugado. É uma potência. O Estado dele decorre. É sua fundação. Dito de outro modo: as Constituições são frutos do caráter inicial dessa modalidade do poder constituinte" ${ }^{\prime 5}$.

Além disso, questiona-se também se não haveria a formação de uma federação ${ }^{66}$ pela UE - como já salientado anteriormente -, entretanto, faltam-lhe alguns requisitos que terminam por deixá-la fora dessa classificação, uma vez que resta clara a inexistência da intenção dos Estados em ceder por completo suas soberanias, bem como a inexistência da indissolubilidade do bloco, fatos que podem ser comprovados a partir do recente fenômeno do Brexit, que pode inaugurar um período de verdadeira fragmentação na região integrada.

seja, não estariam aptos a representar a vontade do povo. A contrario sensu, a análise teria opinião diversa caso fossem eleitos diretamente. Em suma, o problema da Constituição não é o seu conteúdo, mas o fato de ela ter sido redigida sob a forma de um tratado, sem demonstração da vontade popular concretamente" (MARCHIORI NETO; ARAÚJO, 2006, p. 7-8).

SCHWARTZ; MEINERO, 2017, p. 133.

66 "Considerado Estado composto pela doutrina tradicional, pode ser conceituado tendo por base suas características da seguinte forma: (a) é a união de diversos Estados para a formação de um só; (b) estes Estados abrem mão das respectivas soberanias em prol da união, ou da república federativa; (c) estes Estados passam a ter mera autonomia político- -administrativa, autonomia esta extremamente variável conforme a previsão de cada texto constitucional do Estado federal criado, mas possuindo a tríplice função de auto-organização, autogoverno e autoadministração; (d) essa união passa a ser indissolúvel, pois os Estados federados, ou as chamadas unidades federativas, já não mais possuem soberania para decidir se vão - ou não continuar unidos ou separados;12 (e) normalmente as unidades federativas são representadas por uma só pessoa de direito internacional público; (f) as unidades federativas são organizadas por Constituições, portanto, possuem poder constituinte decorrente originário e derivado; (g) é criado, organizado e estruturado através de norma interna, ou seja, a Constituição Federal; (h) é consagrado uma repartição constitucional de competências ou atribuições; (i) alguns autores adicionam a organização legislativa bicameral como sendo uma das características essenciais da forma federativa de Estado" (PINTO, 2013, p. 120). 
Isto posto, Beck, questionado se a UE não teria sido até hoje aparelhada a partir da antiga imagem do Estado nacional, de cooperação entre Estados em determinados setores, $\mathrm{o}$ que, em verdade, teria se tornado seu maior defeito, conclui que esta é um dos maiores desafios para a teoria do Estado, uma vez que se criou uma ordem econômica que questiona o próprio Estado nacional. Beck ${ }^{67}$ prudentemente interroga: "[...] e, se no lugar do antigo projeto agora há de surgir outro projeto político, um projeto de cooperação transnacional do Estado, isso depende do processo político e também do intelectual".

Deveras, para ele “[...] não se pode conceber a UE apenas negativamente, como não-Estado nacional, e sim como experiência de um novo tipo de Estado, especificamente, um Estado transnacional, regulador e cooperativo". Para tanto, se parte do pressuposto de uma concepção de Estado desterritorializado, onde há a imposição de garantias e limites impostos pelos Estados em cooperação, vinculados a partir das amarras de uma força auto limitadora. ${ }^{68}$

É nesse sentido que Habermas, também tratando da UE sob um novo ponto de vista, vai desenvolver uma visão na qual esta pode ser concebida como o próximo passo para termos uma sociedade mundial que se constitui politicamente. Para tanto, em seu livro Sobre a Constituição da Europa (2012), Habermas vai desenvolver um novo diagnóstico com vistas

67 BECK, 2003, p. 49.

68 Beck (2003, p. 216) explica que "foi o que tivemos oportunidade de observar há pouco tempo, na Alemanha, quando da tentativa da coligação entre os social-democratas e os Verdes de abandonar a energia nuclear. Essa política legitimada pela maioria no Parlamento nacional ficou presa em uma rede de acordos internacionais que o governo Kohl celebrou com as vizinhas França e Inglaterra, ambas favoráveis à energia atômica, e que agora prendem também o governo sucessor. Esses contratos vinculam o comércio com energia e lixo atômicos a custos que ameaçam o Estado que pensar em denunciá-los". 
aos desdobramentos decorrentes do Tratado de Lisboa ${ }^{69}$, visando propor uma efetividade na ambição democrática. A partir de sua Teoria Discursiva ${ }^{70}$, Habermas ${ }^{71}$ defende que a proposta da UE somente pode se concretizar efetivamente de forma democrática, com a soberania popular e com uma reconecção dos cidadãos europeus com a comunidade política em que estão inseridos. Portanto, parte do fato de que o primeiro passo a ser dado é a constituição de uma cidadania europeia, onde os cidadãos seriam parte de seus respectivos países, mas também seriam cidadãos europeus o, que, há que ser mencionado, já está ocorrendo.

69 O Tratado de Lisboa foi assinado em 13 de dezembro de 2007 e entrou em vigor em 01 de dezembro de 2009, tendo como objetivo "tornar a UE mais democrática e eficaz e mais apta a resolver problemas a nível mundial, como as alterações climáticas, permitindo-lhe falar a uma só voz" (UNIÃO EUROPEIA, 2017b).

70 A teoria discursiva de Habermas parte inicialmente das concepções decorrentes de sua Teoria da Ação Comunicativa. A fim de melhor elucidar esses termos, André Coelho (2012, p. 46-47) esclarece que "Habermas concebe as sociedades modernas como divididas em dois âmbitos: por um lado, existem os sistemas, nomeadamente o sistema econômico e o sistema político, que são âmbitos especializados de ação racional com vista a fins, funcionando segundo códigos fechados e cegos para valores, movidos por propósitos unitários (lucro e poder, respectivamente) e responsáveis pela reprodução material da sociedade; por outro lado, existe o mundo da vida (em sentido sociológico), a esfera de ação cotidiana que abarca os saberes, valores e ações compartilhadas entre os indivíduos, formado e mantido a partir de interações simbólicas mediadas pela linguagem e responsável pela reprodução simbólica da sociedade, tanto enquanto unidade de cultura como enquanto comunidade solidária. Uma das dificuldades de comunicação entre sistemas e mundo da vida é que ambos não dispõem de uma linguagem comum, sendo o direito particularmente útil enquanto medium de comunicação exatamente por ser igualmente aberto às demandas de um e de outro e conseguir converter os elementos de um para a linguagem do outro". A Teoria da Ação Comunicativa, portanto, é estendida ao direito e transformada no que Habermas vai chamar de Teoria Discursiva do Direito.

71 HABERMAS, 2012b, p. 56. 
Essa conclusão se dá, na medida em que Habermas ${ }^{72}$ salienta que a UE já possui qualidades que lhe proporcionam uma estrutura política, que, entretanto, ainda está presa ao invólucro do Direito da Integração, onde basicamente quem dita as regras é o Poder Executivo. A partir do Tratado de Lisboa, há uma evidente crise de identidade da UE, posto que o Tratado assume um caráter de Constituição, ainda que não tenha sido atribuído esse nome ao mesmo. ${ }^{73} \mathrm{Na}$ realidade, este foi conduzido pelos governos dos Estados Membros e não pelos cidadãos europeus, que efetivamente deteriam legitimidade para aprovar uma Constituição para a Europa. Para o autor, isso somente é possível através da juridificação, ou seja, apenas por intermédio do Direito é que seria possível alcançar a democracia desejada. "Apoiada no modelo deliberativo democrático - com as devidas reflexões sobre soberania e cidadania - a juridificação pressupõe uma procedimentalização para pensar as categorias políticas no modelo transnacional"74.

Verifica-se, pois, que Habermas visa essencialmente elaborar uma concepção de UE na forma de um Estado tradicional, pensamento que não está equivocado, uma vez que a possibilidade de a UE se tornar um Estado efetivamente, ou melhor dito, uma confederação de Estados, ainda que pareça estar fora de cogitação, é um fantasma que assombra os Estados europeus desde a conformação da CECA, nos primórdios da integração regional. Mas se assim fosse, como defende $\mathrm{o}$ autor, tal fato deveria ocorrer com legitimidade $\mathrm{e}$ a partir da expressão de vontade do cidadão europeu.

72 HABERMAS, 2012b, p. 40.

73 Tal fato resta comprovado, na medida em que o Tratado de Lisboa possui objetivos idênticos ao Tratado que estabelece uma Constituição para a Europa: “O Tratado que estabelece uma Constituição para a Europa (2004), com objetivos idênticos aos do Tratado de Lisboa, foi assinado, mas não chegou a ser ratificado" (UNIÃO EUROPEIA, 2017d).

74 ALMEIDA, 2017, p. 2. 
Entretanto, o que se tem em mente no presente estudo é que o invólucro do Direito da Integração deve ser analisado sob o ponto de vista da evolução e não a partir de conceitos clássicos, tendo em vista a complexidade transcendente desses, modificando-se, assim, as estruturas existentes. Isso porque, até mesmo a concepção de democracia é questionada, na medida em que há necessidade de se adequar para incluir a diversidade social. ${ }^{75}$ Nesse sentido, importa ressaltar que

"[...] a ideia das Constituições Escritas modernas está ligada aos conceitos de nação, de povo e de soberania. Ocorre que o Tratado Constitucional Europeu, por sua natureza [...], (re)questiona e (re) posiciona tais pressupostos. Dessa maneira, (re)coloca a interpretação da função das Constituições - e dos Tratados - em um novo nível de discussão. Paradoxal" ${ }^{76}$

No mesmo sentido, Beck ${ }^{77}$ ressalta que "[...] tudo depende da medida em que se cristaliza o projeto político de uma Europa cosmopolita, que já não será estatal-nacional, mas estatal, ou melhor, estatal-cooperativa, estatal reguladora". Para esse autor, ao contrário do exposto anteriormente, a transnacionalização do Estado e da política são seguidos de uma "desdemocratização" dessa última, uma vez que as manobras reguladoras ultrapassam as fronteiras nacionais e escapam ao controle da legislação democrática. Para tanto, defende a passagem do Estado nacional para o Estado cooperativo regulador, no qual, "a nova razão de Estado, que ultrapassa as fronteiras nacionais, incorpora, pois, outro tipo de Estado, o Estado cooperativo apenas regulador, e adquire sua desterritorialização mediante a autolimitação. Entrelaçam-se a dilatação da soberania e a renúncia a ela"78.

75 RODRIGUEZ, 2017, p. 217.

76 SCHWARTZ; MEINERO, 2017, p. 134.

77 BECK, 2003, p. 50.

78 BECK, 2003, p. 216. 
Isto posto, verifica-se que a questão da transnacionalidade é muito mais complexa do que parece, isto é, a UE trata-se, na verdade, de uma forma híbrida de funcionalidade, na medida em que não está totalmente adstrita ao Direito da Integração, mas também não pode ser considerada um Estado ou confederação de Estados, reabrindo-se, por assim dizer, uma discussão proveniente das Teorias de Estado.

\section{Conclusão}

Ao longo desta breve análise pode-se perceber que a globalização traz transformações em diversos ramos da sociedade moderna, muitas dessas, de forma inevitável, tal como ocorre com a transnacionalização das fronteiras do Estado nacional. Dificilmente pode-se falar em um Estado que não resista a essa mudança, mas o fato é que as fronteiras territoriais não são mais o limite da atuação estatal, nem mesmo o limite do agir dos seus cidadãos, havendo uma constante expansão do livre comércio, das facilidades advindas da tecnologia, que terminam por aproximar as pessoas e, assim, reduzir o desconhecimento a respeito das diferenças culturais.

Em que pese ser um ramo do Direito pouco conhecido no Brasil, o Direito da Integração adquire suma importância, uma vez que é a partir dos esquemas de integração que os Estados passam a se relacionar uns com os outros de forma harmônica, coesa e solidária, tendo como pano de fundo um objetivo econômico que, por uma via ou outra, termina deixando transparecer a verdadeira finalidade da integração regional, vinculada à preservação da paz e à eliminação das disputas territoriais. Exemplo disso é o esquema de integração do Mercosul, que visou essencialmente acabar com as disputas entre Argentina, Brasil, Paraguai e Uruguai, de 
modo a evitar um conflito armado nas mesmas proporções daquele conhecido como "Guerra da Tríplice Fronteira", que finalizou em 1870, havendo dizimado a população paraguaia daquela época; do NAFTA, que em que pese não tenha o condão de encerrar totalmente o clima de estranhamento entre Estados Unidos e México, possibilita um pacífico grau de movimentação econômica na região, em termos de livre comércio, sem que isso implique em livre circulação de pessoas; e, também, a tão conhecida UE, onde Alemanha e França também buscaram, no passado, encerrar suas desavenças a partir de uma cooperação regional, destinada, igualmente, à reconstrução da Europa, no Pós-Guerra.

Referidos esquemas - dando-se ênfase à UE - transcenderam os limites primeiramente estabelecidos, irradiando uma nova roupagem, tanto para o Direito da Integração, quanto para a própria estrutura do Estado nacional, que não mais pode ser visto tão somente a partir de suas fronteiras. Os autores, cujas teorias serviram de base para o desenrolar do presente estudo -Beck e Habermas -, chegam, cada um à sua maneira, à conclusão de que a UE deve ser analisada a partir de uma nova roupagem, pois dá ao Estado nacional um novo patamar: Habermas propondo a democratização da Europa; e Beck, uma nova visão de Estado nacional.

Em que pese o desenrolar do estudo tenha pendido para uma visão alternativa à Teoria do Estado, uma vez que se entendeu que a proposta de Habermas fosse levar a UE a um patamar de Superestado democrático, não se pode deixar de dar crédito à proposta do referido autor, uma vez que esta também é uma opção, mas que talvez esteja mais distante da realidade dos dias atuais.

Isto posto, optou-se pela concepção de cooperação transnacional de Beck, que traz uma nova dimensão ao Estado nacional e, ao que parece, ao próprio Direito da In- 
tegração. O que se defende é que a complexidade impelida aos antigos conceitos deve ser analisada a partir da ideia de evolução.

\section{Referências}

ALMEIDA, Juliana Bighetti. A crise da democracia na União Europeia: uma resposta por Jürgen Habermas. In: Seminário Discente do Programa de Pós-Graduação em Ciência Política - USP , 7., 2017, São Paulo. Anais eletrônicos... São Paulo: Conferências FFLCH - USP, 2017. Disponível em: <http:/ / www.conferencias.fflch.usp.br/sdpscp/VIIsemDCP/paper/view/ 1904/345>. Acesso em: 05 fev. 2019.

BECK, Ulrich. Liberdade ou capitalismo: Ulrich Beck conversa com Johannes Willims. Tradução Luiz Antônio Oliveira de Araújo. São Paulo: Editora UNESP, 2003.

BECK, Ulrich. O que é globalização? Equívocos do globalismo: respostas à globalização. Tradução André Carone. São Paulo: Paz e Terra, 1999.

BECK, Ulrich. Sociedade de risco: rumo a uma outra modernidade. Tradução Sebastião Nascimento. São Paulo: Editora 34, 2011.

BIJOS, Leila Maria da Juda. Desafios jurídicos e econômicos para a cooperação técnica internacional na América do Sul. Revista Brasileira de Estudos Políticos, v. 114, p. 223-260, jan./jun. 2017. Disponível em: <https://pos.direito.ufmg. br/rbep/index.php/rbep/article/view/397/381>. Acesso em: 05 fev. 2019.

BONAVIDES, Paulo. A constituinte de 1987-1988 e a restauração do estado de direito. In: CANOTILHO, J. J. Gomes; MENDES, Gilmar Ferreira; SARLET, Ingo Wolfgang; 
STRECK, Lenio Luiz. (Coords.). Comentários à constituição do Brasil. São Paulo: Saraiva/Almedina, 2013. p. 53-59. Livro eletrônico.

BRASIL. Supremo Tribunal Federal. Carta Rogatória no 8279, Tribunal Pleno. Agravante: Coagulantes Argentinos S.A. Relator Ministro: Celso de Mello. Brasília, DF. 17 de junho de 1998. Disponível em: <http://www.stf.jus.br/portal/ jurisprudencia/listarJurisprudencia.asp?s1=\%28CR $\% 24 \%$ 2ESCLA $\% 2 \mathrm{E}+\mathrm{E}+8279 \%$ 2ENUME $\% 2 \mathrm{E} \% 29+\mathrm{OU}+\% 28 \mathrm{CR} \%$ 2EACMS $\% 2 \mathrm{E}+\mathrm{ADJ} 2+8279 \% 2 \mathrm{EACMS} \% 2 \mathrm{E} \% 29 \&$ base=base Acordaos\&url=http://tinyurl.com/bcopsof $>$. Acesso em: 05 fev. 2019.

CHURCHILL, Winston. Discurso de Winston Churchill. 19 set. 1946. Discurso pronunciado na Universidade de Zurique. Disponível em: <http://www.itamaraty.gov.br/pt-BR/ sem-categoria/14297-discurso-de-winston-churchill-na-universidade-de-zurique-19-de-setembro-de-1946>. Acesso em: 05 fev. 2019.

COELHO, André Luiz Souza. A gênese lógica do sistema dos direitos fundamentais em Habermas. 2012. 160 f. Dissertação (Mestrado em Filosofia) - Programa de Pós-Graduação em Filosofia, Universidade Federal de Santa Catarina, Florianópolis, 2012. Disponível em: <https:// repositorio.ufsc. br/xmlui/ bitstream/handle/123456789/100406/313877. pdf?sequence=1>. Acesso em: 05 fev. 2019.

FORNASIER, Mateus de Oliveira; MENDES, Tiago Meyer. Constitucionalismo e globalização: entre ordens internas e externas de direitos. In: Revista Brasileira de Estudos Politicos, v. 113, p. 533-570, jul./dez. 2016. Disponível em: <https:// pos.direito.ufmg.br/rbep/index.php/rbep/article/ view/444/371>. Acesso em: 05 fev. 2019. 
HABERMAS, Jürgen. A constelação pós-nacional: ensaios políticos. Tradução Márcio Seligmann Silva. São Paulo: Littera Mundi, 2001.

HABERMAS, Jürgen. Direito e democracia: entre facticidade e validade. Tradução Flávio Beno Siebeneichler. v. II. 2. ed. Rio de Janeiro: Tempo Brasileiro, 2003.

HABERMAS, Jürgen. Direito e democracia: entre facticidade e validade. Tradução Flávio Beno Siebeneichler. v. I. Rio de Janeiro: Tempo Brasileiro, 2012a. Reimpressão.

HABERMAS, Jürgen. Sobre a constituição da Europa: um ensaio. Tradução Denilson Luis Werle, Luiz Repa e Rúrion Melo. São Paulo: Unesp, 2012b.

MACHADO, Diego Pereira. Direito da união europeia. São Paulo: Saraiva, 2013.

MARCHIORI NETO, Daniel Lena; ARAÚJO, Luiz Ernani Bonesso. Constituição europeia: dilemas da consolidação de uma soberania supranacional. In: Revista dos Alunos do Programa de Pós-Graduação em Integração Latino-Americana - UFSM, Santa Maria, v. 2, n. 2, 2006. Disponível em: <http:/ / coral.ufsm.br/mila/publicacoes/reppilla/edicao02-2006/2006\%20\%20artigo\%201.pdf>. Acesso em: 05 fev. 2019.

MARSHALL, George. Discurso de George Marshall. 05 jun. 1947. Discurso pronunciado na Universidade de Harvard. Disponível em: <https://webcache.googleusercontent. com/search?q=cache:N3WkllpVs-cJ:https:/ / dialnet.unirioja.es/descarga/articulo/2495018.pdf $+\& c d=1 \&$ hl=pt-BR\&ct=clnk\&gl=br>. Acesso em: 05 fev. 2019.

MEZZAROBA, Orides; MONTEIRO, Cláudia Servilha. Manual de Metodologia da Pesquisa no Direito. São Paulo: Saraiva, 2003. 
NEGRO, Sandra Cecilia (Dir.). Derecho de la integración: manual. Montevidéo: B de F, 2010.

OCAMPO, Raúl Granillo. Direito internacional público da integração. Tradução Sérgio Duarte. Rio de Janeiro: Esevier, 2009.

PETRUCCIANI, Stefano. Modelos de filosofia política. Tradução José Raimundo Vidigal. São Paulo: Paulus, 2014.

PINTO, Kleber Couto. Curso de teoria geral do estado: fundamento do direito constitucional positivo. São Paulo: Atlas, 2013. Livro eletrônico.

PROYECTO MESOAMÉRICA. Reglamento de funcionamiento del proyecto de integración y desarrollo mesoamérica, Guatemala, 21 jun. 2016. Disponível em: <http:/ / www.proyectomesoamerica.org/phocadownload/Estatutos/reglamentoPM-Firmado/Reglamento\%20de\% 20Funcionamiento \% 20 del\%20PM_firmado.pdf>. Acesso em: 05 fev. 2019.

RODRIGUEZ, José Rodrigo. Democracia e feminismo: qual racionalidade? Revista Brasileira de Estudos Politicos, v. 114, p. 199-222, jan./jun. 2017. Disponível em: <https:/ / pos.direito. ufmg.br/rbep/index.php/rbep/article/view/466/390>. Acesso em: 05 fev. 2019.

SANTIN, Janaína Rigo. Estado, sociedade civil e legitimação do poder. Revista Brasileira de Estudos Políticos, v. 111, p. 247-274, jul./dez. 2015. Disponível em: <https:// pos.direito.ufmg.br/rbep/index.php/rbep/article/view/P.00347191.2016V111P247/329>. Acesso em: 05 fev. 2019.

SCHUMAN, Robert. Declaración de Robert Schuman. 09 mai. 1950. Discurso pronunciado pelo Ministro francês de Assuntos Exteriores. Disponível em: <https://europa. eu/european-union/about-eu/symbols/europe-day/ schuman-declaration_es>. Acesso em: 05 fev. 2019. 
SCHWARTZ, Germano; MEINERO, Fernando. O paradoxo do tratado constitucional europeu: entre o planejamento e a evolução da Europa comunitária. In: Revista de Investigações Constitucionais, Curitiba, v. 4, n. 2, p. 131-146, maio/ago. 2017. Disponível em: <http:/ / revistas.ufpr.br/rinc/article/ view/48093/33213>. Acesso em: 05 fev. 2019.

TRATADO de Maastricht sobre a União Europeia. EUR-Lex - acesso ao direito da união europeia. [S.1.], 15 out. 2010. Disponível em: <http:/ / eur-lex.europa.eu/legal-content/PT/ TXT/?uri=LEGISSUM\%3Axy0026>. Acesso em: 05 fev. 2019.

UNIÃO EUROPEIA. A UE em poucas palavras. [S.1.], 2017a. Disponível em: <https:// europa.eu/european-union/ about-eu/eu-in-brief_pt>. Acesso em: 05 fev. 2019.

UNIÃO EUROPEIA. Os fundadores da UE. [S.1.], 2017b. Disponível em: <https:/ / europa.eu/european-union/ about-eu/history/founding-fathers_pt\#box_8>. Acesso em 05 fev. 2019.

UNIÃO EUROPEIA. O termo de vigência do tratado CECA. [S.l.], 2017c. Disponível em: <http://europa.eu/ecsc/index_pt.htm>. Acesso em: 05 fev. 2019.

UNIÃO EUROPEIA. Tratados da UE. [S.1.], 2017d. Disponível em: <https:/ / europa.eu/european-union/law/treaties_pt>. Acesso em: 05 fev. 2019.

VESPAZIANI, Alberto. The crisis of the European Union: apocalypse now? In: Revista Brasileira de Estudos Politicos, v. 114, p. 13-29, jan./jun. 2017. Disponível em: <https:// pos.direito.ufmg.br/rbep/index.php/rbep/article/ view/462/386>. Acesso em: 05 fev. 2019.

VIEIRA, Luciane Klein. Brexit: ¿y ahora? Consecuencias jurídicas de la retirada del Reino Unido de la Unión Europea. In: Revista Peruana de Derecho Internacional. Tomo LXVI. N 154. 2016. 
VIEIRA, Luciane Klein. Interpretação e Aplicação Uniforme do Direito da Integração: União Europeia, Comunidade Andina, Sistema da Integração Centro-Americana e Mercosul. Curitiba: Juruá, 2013.

Recebido em 18/07/2018.

Aprovado em 31/01/2019.

\section{Luciane Klein Vieira}

E-mail: lucianekleinvieira@yahoo.com.br

Maria Cândida Simon Azevedo

E-mail:Ikandida8@hotmail.com 
